\title{
Una mirada crítica a la aplicación del amparo de pobreza en el proceso arbitral colombiano
}

\author{
A Critical View of the Application of the Poverty Protection \\ in the Arbitration Procedure in Colombia \\ Um olhar crítico sobre a aplicação do amparo da pobreza \\ no processo de arbitragem colombiano
}

\author{
LUISA María Brito Nieto* \\ LAURA ESTEPHANÍA HUERTAS MONTERO*
}

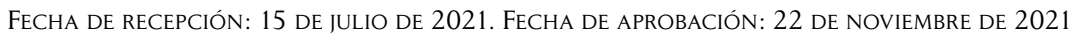

Doi: https://doi.org/10.12804/revistas.urosario.edu.co/sociojuridicos/a.10841

Para citar este artículo: Brito Nieto, L. M., \& Huertas Montero, L. E. (2022). Una mirada crítica a la aplicación del amparo de pobreza en el proceso arbitral colombiano. Estudios Socio-Jurídicos, 24(1), 97-125. https://doi. org/10.12804/revistas.urosario.edu.co/sociojuridicos/a.10841

\section{RESUMEN}

El presente artículo tiene como finalidad analizar la aplicabilidad teórica y práctica del amparo de pobreza en el proceso arbitral, y evaluar la posibilidad de emplear el arbitraje social como una herramienta para la búsqueda de una justicia incluyente e igualitaria. El amparo de pobreza se fundamenta en la necesidad de lograr el acceso a la administración de justicia y la igualdad material, brindando a las personas de bajos recursos económicos una posibilidad de resolver sus conflictos. Sin embargo, el arbitraje no parece ser compatible con dicha lógica, porque, dada su naturaleza, para acceder a este proceso se hace necesario sufragar ciertos costos.

Palabras clave: arbitraje; amparo de pobreza; arbitraje social.

* Docente investigadora de la Universidad Externado de Colombia. Correo electrónico: luisa.brito@uexternado.edu.co. ORCID: https://orcid.org/0000-0002-4481-8811

** Docente investigadora de la Universidad Externado de Colombia. Correo electrónico: laura.huertas@uexternado.edu.co. ORCID: https://orcid.org/0000-0001-9766-432 


\section{ABSTRACT}

The purpose of this article is to present the analysis of the theoretical and practical applicability of poverty protection in the arbitration procedure and the evaluation of the possibility of using social arbitration as a tool for the search for inclusive and egalitarian justice. Poverty protection is based on the need to achieve access to justice and material equality, giving people with low economic resources a chance to solve their conflicts. However, arbitration does not seem compatible with this logic because, given its nature, to access it, the payment of certain costs is necessary.

Keywords: Arbitration; poverty protection; social arbitration.

\section{RESUMO}

O objetivo deste artigo é analisar a aplicabilidade teórica e prática da proteção à pobreza no processo de arbitragem e avaliar a possibilidade de utilizar a arbitragem social como ferramenta de busca por uma justiça inclusiva e igualitária. A proteção da pobreza baseia-se na necessidade de conseguir acesso à administração da justiça e igualdade material, dando às pessoas com poucos recursos econômicos uma chance de resolver seus conflitos. No entanto, a arbitragem não parece ser compatível com esta lógica, pois dada a sua natureza, para ter acesso a este processo é necessário custear determinados gastos.

Palavras-chave: arbitragem; proteção da pobreza; arbitragem social. 


\section{Introducción}

El amparo de pobreza es una figura procesal contemplada en los artículos 151 y siguientes de la Ley 1564 de 2012 (en adelante CGP), que permite que la persona que no se halle en capacidad de atender los gastos del proceso sin menoscabar su propia subsistencia, o la de a quienes por ley debe alimentos, sea exonerada de asumir dichos costos. Así las cosas, esta institución propende por garantizar la igualdad real de las partes y el acceso efectivo a la administración de justicia.

Por su parte, y de acuerdo con el artículo 13 de la Ley 1563 de 2012 (Estatuto de Arbitraje), el amparo de pobreza también aplicará al proceso arbitral en los términos del estatuto procesal civil, con ciertas reglas particulares.

A pesar de lo anterior, y dado que el arbitraje es un mecanismo alternativo de solución de controversias que mayoritariamente se caracteriza por ser oneroso - al causarse honorarios a favor de los árbitros y, generalmente, gastos de administración del arbitraje-, resulta imperativo analizar la compatibilidad y las vicisitudes tanto teóricas como prácticas de la aplicación de la figura del amparo de pobreza en el arbitraje.

Con el propósito mencionado, se analizará en primera medida el concepto y la finalidad del amparo de pobreza, la regulación de esta figura en la regulación del arbitraje nacional y la posibilidad de conceder el amparo a personas jurídicas.

En segundo lugar, nos adentraremos en las vicisitudes teóricas y prácticas que surgen de la aplicación del amparo de pobreza en el arbitraje, habiendo identificado como tales las siguientes: i) la naturaleza mayoritariamente onerosa del arbitraje; ii) el momento en el que se solicita el amparo de pobreza; iii) el alcance del amparo de pobreza, específicamente si la exoneración de costos a favor del amparado incluye también los gastos que se causen a favor del centro de arbitraje; iv) el evento en el cual ambas partes soliciten el amparo de pobreza; v) el caso en el que el amparo es solicitado por alguna de las partes, y la otra no consigna su porcentaje de honorarios y gastos; vi) el alcance del amparo de pobreza, particularmente si hay lugar a condenar en costas al amparado; y vii) la eficacia jurídica de incluir el amparo de pobreza en el pacto arbitral. 
Habiendo identificado y analizado las principales vicisitudes de aplicar el amparo de pobreza al arbitraje, efectuaremos una crítica a la regulación actual y se estudiará el arbitraje social como una posible solución -aunque insuficiente como se encuentra contemplada actualmente- para garantizar la igualdad real de las partes y el acceso efectivo a la administración de justicia en los eventos en los cuales una o ambas partes que hayan pactado acudir a arbitraje para dirimir determinadas controversias se encuentren en una difícil situación económica.

Para llevar a cabo el estudio descrito, se utilizará una metodología crítica, tomando como sustento las fuentes normativas, jurisprudenciales y doctrinales más relevantes sobre la materia.

\section{El amparo de pobreza en el arbitraje}

De forma previa a analizar las vicisitudes teóricas y prácticas del amparo de pobreza en el arbitraje, efectuaremos un acercamiento al concepto y finalidad del amparo de pobreza en la normatividad procesal y en el Estatuto de Arbitraje.

\section{Concepto y finalidad del amparo de pobreza}

Como fue anunciado, el amparo de pobreza es una institución que busca materializar la igualdad real entre las partes dentro de un proceso judicial, permitiendo que aquella persona que se encuentre en una situación económica considerablemente difícil, o en una condición de extrema pobreza o marginalidad, sea exonerada de la carga de asumir ciertos costos que se presentan de manera inevitable a lo largo de un proceso judicial. El propósito de esta figura es otorgarle una protección especial a ese sujeto para que no deba escoger entre atender su congrua y mínima subsistencia y la de aquellas personas a las que por ley debe alimentos o costear los gastos de un proceso judicial en el que tiene interés (Huertas Montero, 2018, p. 297), en la medida en que su dignidad humana y su derecho al acceso efectivo a la administración de justicia son derechos fundamentales con la misma jerarquía. 
La figura del amparo de pobreza es, entonces, una medida de especial protección (López Blanco, 2016, p. 1061) y una medida correctiva y equilibrante que busca garantizar la igualdad en situaciones que originalmente eran de desigualdad, pues es un deber del Estado asegurar a todos los ciudadanos, en particular a los que no tengan recursos económicos, la defensa de sus derechos. Supone un beneficio que se otorga solo al sujeto procesal que se encuentra en esa situación de hecho (pobreza) que esta institución busca corregir (Corte Constitucional, Sentencia T-114 de 2007, M. P.: Nilson Pinilla Pinilla). ${ }^{1}$

La preocupación por garantizar el derecho fundamental al acceso efectivo a la administración de justicia y a la tutela judicial efectiva de las personas de escasos recursos económicos o en estado de marginalidad o crisis económica no es solo del ordenamiento jurídico colombiano, sino que ha sido una preocupación constante en los ordenamientos de varios países latinoamericanos. En el anteproyecto del Código Procesal Civil Modelo para Iberoamérica, redactado por el Instituto Iberoamericano de Derecho Procesal, se afirmó como una de las bases generales comunes para los códigos latinoamericanos de procedimiento civil. ${ }^{2}$

Siguiendo este postulado, varios códigos de procedimiento civil latinoamericanos han consagrado expresamente la figura del amparo de pobreza, denominada justicia gratuita en el derecho venezolano (Código

1 Cfr. en similar sentido: López Blanco (2016, pp. 1066 y 1067); Tribunal Contencioso Administrativo del Cauca, auto del 17 de marzo de 2010, M. P.: Naun Mirawal Muñoz, Exp.: 2008-000420-01; Consejo de Estado, Sala de lo Contencioso Administrativo, auto del 4 de junio de 1981, C. P.: Eduardo Suescún; Corte Suprema de Justicia, Sala de Casación Civil, auto del 14 de diciembre de 1983, M. P.: Jorge Salcedo Segura; Corte Constitucional, Sentencia T-339 de 2018, M. P.: Luis Guillermo Guerrero Pérez, entre otros. Frente a la procedencia del amparo, un sector de la doctrina ha expresado que existe controversia en cuanto a lo que debe entenderse por pobre y, por ende, qué tipo de sujetos podrían estar legitimados para solicitar este beneficio, pues actualmente no hay ningún criterio objetivo que determine esta circunstancia (López Blanco, 2016, pp. 1062-1063). Sin embargo, en el Código Judicial de Cundinamarca del 11 de noviembre de 1958 se concedía el amparo de pobreza a aquellas personas que no tuvieran una renta anual de por lo menos 140 pesos (arts. 1216 a 1234). Este criterio de renta, por efectos de la inflación, se subió a 180 pesos anuales mediante la Ley 105 de 1980 (art. 288), y se eliminó con la Ley 103 de 1923 (art. 1901).

2 En el cual se señaló lo siguiente: “[...] Quien carezca de los medios económicos para atender los gastos del proceso debe recibir el amparo o beneficio de pobreza, que incluirá el patrocinio judicial a través de los colegios de abogados o por designación del mismo juez de la causa cuando aquellos no existan, o por otro sistema de igual resultado" (punto 34, tema II). 
de Procedimiento Civil de Venezuela, arts. 175 a 182), ${ }^{3}$ auxiliatoria de pobreza en el proceso civil uruguayo (Código General del Proceso de Uruguay, arts. 89, 404 y 406) ${ }^{4}$ o asistencia jurídica gratuita en el derecho procesal civil nicaragüense (Código de Procedimiento Civil -Ley 902 del 4 de junio de 2015-, arts. 86, 221, 318, 377 y 880). ${ }^{5}$

Finalmente, para lo que nos convoca, el CGP regula el amparo de pobreza en sus artículos 151 a 158. El artículo 158 de este estatuto procesal establece que "se concederá el amparo de pobreza a la persona que no se halle en capacidad de atender los gastos del proceso sin menoscabo de lo necesario para su propia subsistencia y la de las personas a quienes por ley debe alimentos, salvo cuando pretenda hacer valer un derecho litigioso a título oneroso". ${ }^{6}$

3 Establece que el servicio de justicia gratuita puede ser solicitado por cualquiera de las partes y en cualquier instancia del proceso, y el juez resolverá sobre la concesión de este beneficio luego del decreto de pruebas. En este ordenamiento jurídico se concede el beneficio a todas aquellas personas que no tengan los medios suficientes para litigar o hacer valer sus derechos; y es posible obtenerlo, sin declaratoria judicial previa, si la persona percibe un ingreso que no exceda del triple del salario mínimo obligatorio fijado por el ejecutivo nacional y las instituciones de beneficencia pública. Las personas beneficiadas por este mecanismo legal se encuentran exentas de pagar aranceles, tasas, contribuciones, timbres fiscales y honorarios de auxiliares de justicia, y se les nombra por el juez un abogado defensor que represente sus intereses de forma gratuita.

4 Se define como aquella solicitud que se tramita a través del proceso de jurisdicción voluntaria con convocatoria de la contraparte a una audiencia oral antes de conceder el beneficio a la persona. Los auxiliados por pobreza quedan exentos, entre otras cosas, de pagar los gastos de publicaciones por edictos (cuando hay personas indeterminadas o no se conoce el domicilio de estas).

5 En virtud de la cual la parte debe acreditar que carece de los recursos necesarios para litigar y se le designa en esos casos a un funcionario de la defensoría pública de ese país para que represente sus intereses. Así mismo, quienes gocen de este beneficio de la asistencia jurídica gratuita quedan a salvo de pagar costas procesales (art. 221), no tienen la obligación de aportar el dictamen pericial con la demanda o con la contestación, sino que podrán solicitarle al juez la designación de un perito (art. 318); se encuentran exentos de prestar caución para la práctica de medidas cautelares (art. 377); y no deben pagar los honorarios de los peritos, los cuales correrán a cargo de la administración de justicia (art. 880).

6 Frente a la procedencia del amparo de pobreza, y aun cuando no sea el objeto central de este artículo, es menester destacar que en el artículo 152 del CGP se suprimió la palabra "adquirido" de la redacción que venía del artículo 160 del anterior Código de Procedimiento Civil, planteándose de manera errada y quizá por un error de tipo en el trámite del artículo ante el Congreso de la República que la procedencia del amparo de pobreza se encuentra condicionada a la naturaleza del derecho que se reclama: es decir, solo se podrá pedir el amparo de pobreza si se reclaman derechos a título gratuito, como, por ejemplo, las herencias y los legados, y no a título oneroso. Sin embargo, la interpretación de esta norma en este sentido luciría desproporcionada y contraria al acceso efectivo a la administración de justicia, pues dejaría por fuera a muchas personas que se encuentren en condiciones económicas difíciles y precarias y que desean reclamar ante el aparato judicial la protección de sus derechos 
De esta manera, en el ordenamiento procesal colombiano cualquier persona que manifieste bajo la gravedad de juramento al juez que se encuentra en una condición económica que no le permite atender los gastos de un determinado proceso judicial sin deteriorar su propia subsistencia digna o la de aquellos a quienes por ley está obligado a otorgar alimentos puede acceder al amparo de pobreza, sin que existan condiciones objetivas que permitan determinar quién es pobre, como sí sucede, por ejemplo, en el ordenamiento procesal venezolano (Código de Procedimiento Civil de Venezuela, art. 178).

Así mismo, quienes sean amparados por pobres no estarán obligados a prestar cauciones procesales ni a pagar expensas, honorarios de auxiliares de la justicia u otros gastos de la actuación, como, por ejemplo, los gastos para la práctica de pruebas de oficio, ni serán condenados a pagar costas procesales; y podrá designárseles, si así lo requieren, un apoderado de oficio para que los represente en el proceso. El amparo de pobreza no tiene efectos retroactivos, por lo que el amparado pobre solo gozará de estos beneficios desde la presentación de la solicitud (Código General del Proceso, art. 154).

Finalmente, comoquiera que el fin último del amparo de pobreza es garantizar el acceso a la administración de justicia, consideramos preciso detenernos en la relación entre el arbitraje como mecanismo alternativo de solución de controversias y dicho derecho fundamental.

El acceso a la administración de justicia ha sido entendido como el derecho que el Estado reconoce a los asociados de acudir ante las autoridades que ejerzan funciones jurisdiccionales, en condiciones de igualdad, y con plena observancia de las garantías procesales previstas en el ordenamiento jurídico (Corte Constitucional, Sentencia T-799 de 2011, M. P.: Humberto Antonio Sierra Porto).?

sustanciales y el pago de indemnizaciones, compensaciones o la realización efectiva de obligaciones de dar dinero o de dar cosas distintas a dinero derivadas de negocios jurídicos onerosos. La intención del artículo 160 del anterior Código de Procedimiento Civil era la de no conceder el amparo de pobreza cuando la parte que alegaba el reclamo de algún derecho ante la jurisdicción lo había adquirido por cesión de derechos o compra de la posición jurídica de alguna de las partes, con el fin de evitar que se produjera fraude a la norma procesal.

7 Ver también: Corte Constitucional, Sentencia C-059 de 1993, M. P.: Alejandro Martínez Caballero; Corte Constitucional, Sentencia SU-091 de 2000, M. P.: Álvaro Tafur Galvis; Corte Constitucional, Sentencia T-608 de 2019, M. P.: Gloria Stella Ortiz Delgado. 
Con el propósito de garantizar dicho derecho, el Estado ha tenido que prever mecanismos alternativos para la resolución eficiente de los conflictos. Por ello, la Constitución Política prevé que ciertos particulares, entre ellos los árbitros, pueden estar investidos transitoriamente de la función pública de administrar justicia (Constitución Política, art. 116). Así las cosas, el arbitraje es una de las formas por medio de las cuales el Estado procura garantizar el derecho fundamental al acceso a la administración de justicia (Sánchez \& Rodríguez, 2020, pp. 277-297).

\section{Regulación del amparo de pobreza en el Estatuto de Arbitraje}

A pesar de resultar a primera vista contradictoria su aplicación en un sistema de justicia pagada (Otero, 2019, p. 444), de conformidad con el artículo 13 de la Ley 1563 de 2012, el amparo de pobreza podrá concederse en el proceso arbitral, de forma parcial o total, de acuerdo con la normatividad procesal civil. Sin embargo, a pesar de la remisión expresa a la normatividad procesal civil, el artículo 13 del Estatuto de Arbitraje consagra ciertas particularidades acerca del amparo de pobreza en el proceso arbitral (Rodríguez, 2012, p. 13).

El referido artículo 13 dispone que, en el evento en el que hubiere lugar a la designación de apoderado, dicha designación se efectuará mediante sorteo ${ }^{8}$ entre los abogados que se encuentren en la lista de árbitros del centro de arbitraje de que se trate, a menos que el interesado designe su apoderado.

Por otra parte, señala la disposición normativa mencionada que, "sin perjuicio de lo que resuelva el laudo sobre costas, el amparado quedará exonerado del pago de los honorarios y gastos del tribunal arbitral [...]". De este aparte de la norma es preciso efectuar dos anotaciones. En primera medida, el amparado por pobre no deberá pagar los honorarios y gastos del tribunal arbitral, de forma que se excluyen del amparo de pobreza, al menos de la literalidad de la norma, las erogaciones que se causen por concepto de gastos del centro de arbitraje, en el evento en

8 Es preciso traer a colación que el término utilizado por el artículo 13 de la Ley 1563 de 2012 es el siguiente: "[...] a la suerte entre los abogados incluidos en la lista de árbitros del respectivo centro de arbitraje" (cursiva nuestra). 
el que se trate de un arbitraje institucional. Por otro lado, del aparte del artículo en cita también se resalta que dicha exoneración del pago de los honorarios y gastos del tribunal se realiza sin perjuicio de lo que en el laudo se resuelva respecto de las costas, lo que conlleva imperativamente a cuestionarnos acerca de si es posible condenar al amparado en costas en el laudo arbitral.

Finalmente, el tan mencionado artículo 13 del Estatuto de Arbitraje preceptúa que, a pesar de que de que a alguna de las partes le sea concedido el amparo de pobreza, no le corresponderá a la otra parte sufragar lo que al amparado le hubiese correspondido pagar. Así las cosas, y conforme se dispuso en la ponencia para segundo debate ante la Cámara de Representantes del proyecto de ley que derivó en la Ley 1563 de 2012, el tribunal se quedará sin dicho porcentaje de los gastos y honorarios (Congreso de la República, Gaceta No 312 de 2012).

En todo caso, sobre las mencionadas particularidades de la norma regulatoria del amparo de pobreza en el arbitraje profundizaremos en el acápite ulterior.

\section{Posibilidad de conceder el amparo de pobreza a personas jurídicas}

De la literalidad del artículo 151 del CGP, podría deducirse que el amparo de pobreza procede únicamente para personas naturales, comoquiera que hace referencia a que se concederá a quienes no puedan atender los gastos del proceso sin menoscabar su propia subsistencia o la de las personas a quienes se debe alimentos.

Dicha postura fue la que inicialmente desarrolló la jurisprudencia, la cual aseveraba que el amparo de pobreza era un beneficio previsto exclusivamente para las personas naturales, debido a que las condiciones mencionadas en el párrafo anterior solamente eran predicables de ellas, y no de las personas jurídicas (Consejo de Estado, Sección Cuarta, auto del $1^{\circ}$ de febrero de 2002, C. P.: Juan Palacio).

No obstante, y de forma posterior, jurisprudencialmente se abrió la posibilidad de que el amparo de pobreza cobije también a las personas jurídicas que se encuentren en una situación financiera crítica, y que, por tal razón, no se hallen en condiciones de atender los gastos 
del proceso sin generar su extinción desde una perspectiva económica (Corte Constitucional, Sentencia C-668 de 2016, M. P.: Alberto Rojas).9

Sin duda, la posibilidad de que el amparo de pobreza sea concedido a las personas jurídicas garantiza el acceso efectivo a la administración de justicia, consagrado en el artículo 229 de la Constitución Política, toda vez que las personas jurídicas, por su carácter de tales, no se encuentran exentas de hallarse en una crisis económica de tal entidad que no puedan asumir los costos de un proceso judicial sin poner en peligro su existencia. Tal circunstancia sucede con frecuencia, por ejemplo, en el evento de reorganización o liquidación de una sociedad (Quintero, 2016). En todo caso, dicha alternativa debe ser excepcional, y el operador judicial deberá valorar en cada caso concreto la procedencia de conceder el amparo (Consejo de Estado, Sección Cuarta, auto del 3 de mayo de 2007, C. P.: Ligia López), con el inconveniente de que ni la ley procesal ni la jurisprudencia contemplan parámetros claros para el juez que debe estudiar una solicitud de amparo de pobreza.

Finalmente, resulta preciso mencionar que el hecho de que a las personas jurídicas se les pueda conceder el amparo de pobreza genera que esta figura se presente con más frecuencia en el arbitraje, comoquiera que por las características propias ${ }^{10}$ de este mecanismo alternativo de solución de conflictos su utilización resulta más común para resolver controversias en las que intervengan personas jurídicas que aquellas en las que se encuentren involucradas personas naturales.

\section{Vicisitudes teóricas y prácticas de la aplicación del amparo de pobreza en el arbitraje}

Habiendo estudiado la posibilidad de solicitar el amparo de pobreza en el proceso arbitral, resulta imperativo analizar algunas vicisitudes teóricas y prácticas que se han identificado tanto de la normatividad

9 En similar sentido: Corte Suprema de Justicia, Sala de Casación Civil, Auto 45 del $1^{\circ}$ de agosto de 2003, M. P.: Silvio Fernando Trejos.

10 Principalmente por: i) la especialidad de los árbitros, ii) su mayor celeridad y iii) su carácter oneroso. 
contentiva de dicha alternativa como de la compatibilidad misma de la figura con el trámite arbitral.

\section{El arbitraje es eminentemente oneroso}

Como fue mencionado en antecedencia, la institución del amparo de pobreza tiene, como consecuencia práctica principal, que se le exonere al amparado por pobre de prestar cauciones procesales, de pagar expensas, honorarios de auxiliares de justicia y otros gastos que se generen en el proceso (CGP, art. 154).

Por su parte, y para efectos del presente escrito, resulta preciso destacar dos características del proceso arbitral: i) la voluntariedad y ii) su onerosidad. La voluntariedad hace referencia a que solamente mediante el acuerdo de voluntades de las partes ciertas controversias ${ }^{11}$ pueden ser dirimidas mediante arbitraje (Uribe, 2013, pp. 148-149; Mancipe \& Hernández, 2019; López \& Silva, 2018, pp. 46). ${ }^{12}$

Por otro lado, el arbitraje es eminentemente oneroso, es decir, deferir la solución de ciertos conflictos a un tribunal arbitral implica para las partes asumir el pago de los honorarios de los árbitros y los gastos del arbitraje (Sanabria, 2017, p. 290), lo que puede resultar un inconveniente para quienes no cuentan con la suficiente solvencia (Bennetti, 2001, p. 19; Monroy, 2011, p. 8). ${ }^{13}$ El costo del arbitraje se fundamenta en que son particulares transitoriamente investidos de la función de administrar justicia quienes conformarán el tribunal, los cuales naturalmente deben ser remunerados, así como también las partes deberán reconocer los gastos que genere el proceso, dentro de los cuales se incluirán los relativos al centro de arbitraje por la administración del trámite, en el evento en el que se trate de un arbitraje institucional.

En consecuencia, y sin pretender desconocer que el propósito del amparo de pobreza es la garantía de la igualdad real de las partes, al menos de forma teórica sí existe una contradicción entre la naturaleza

11 Conforme con el artículo $1^{\circ}$ de la Ley 1563 de 2012, pueden dirimirse mediante arbitraje los "asuntos de libre disposición o aquellos que la ley autorice".

12 Ver también: Corte Constitucional, Sentencia T-186 de 2015, M. P.: Luis Guerrero.

13 Ver también: Corte Constitucional, Sentencia SU-174 de 2007, M. P.: Manuel Cepeda; Corte Constitucional, Sentencia C-330 de 2012, M. P.: Humberto Sierra. 
misma de esta institución, la cual implica que una de las partes no asuma los gastos del proceso por su condición económica particular, y el arbitraje, que se caracteriza precisamente por implicar ciertos costos para las partes como consecuencia de su decisión voluntaria de no acudir a los jueces estatales para dirimir sus conflictos. Esta incompatibilidad teórica resulta relevante comoquiera que se refleja en algunas vicisitudes que se presentan en la práctica al aplicar la figura del amparo de pobreza al arbitraje, como se verá más adelante.

\section{Momento de la solicitud del amparo de pobreza en el proceso arbitral}

El artículo 13 de la Ley 1563 de 2012 nada dispone respecto del momento en el que debe llevarse a cabo la solicitud del amparo de pobreza en el proceso arbitral, no obstante, y como ya se ha mencionado, dicho artículo refiere a la normatividad procesal civil. Acerca del particular, el artículo 152 del CGP preceptúa que el amparo de pobreza podrá solicitarse: i) por el presunto demandante antes de presentar la demanda; o ii) por cualquiera de las partes, durante el curso del proceso.

En relación con la posibilidad de solicitar el amparo de pobreza antes de presentar la demanda, resulta preciso mencionar que consideramos completamente viable incluir un acuerdo sobre el amparo de pobreza en el pacto arbitral, asunto que se tratará en acápite posterior.

Por otro lado, si bien la regla según la cual el amparo de pobreza puede solicitarse de forma anterior a la presentación de la demanda resulta teóricamente aplicable al proceso arbitral, en la práctica no es del todo clara su aplicación.

La Directiva 5 de 2017 del Centro de Arbitraje y Conciliación de la Cámara de Comercio de Bogotá regula el pago de gastos iniciales en las solicitudes de amparo de pobreza. El artículo $1^{\circ}$ de la referida directiva indica que en el evento en el que se radique una solicitud de amparo de pobreza se procederá a realizar una exoneración meramente parcial de los gastos iniciales del arbitraje. Ahora bien, y de acuerdo con su artículo $2^{\circ}$, en el evento en el que el tribunal decidiere no conceder 
el amparo, el convocante deberá cancelar el valor correspondiente a la totalidad de los gastos iniciales. ${ }^{14}$

De la regulación antes mencionada, resulta imperativo cuestionarse si la exoneración parcial -y no total- de los gastos iniciales del arbitraje limita el acceso a la administración de justicia de quienes, aun careciendo de los medios económicos suficientes para iniciar el trámite arbitral, se les exige cancelar una suma de dinero para que su solicitud de amparo de pobreza sea estudiada.

Sin duda alguna, al indagar por una respuesta al interrogante planteado, salta a la vista la incompatibilidad teórica entre el arbitraje y el amparo de pobreza, antes analizada. Si bien es cierto que existiría una barrera para el eventual solicitante del amparo de pobreza al tener que cancelar ciertos gastos para radicar su solicitud, lo cierto es que existen gastos que no resultan cubiertos por el amparo de pobreza, consistentes en los gastos del centro de arbitraje, asunto que se analizará en el acápite siguiente.

\section{¿Los gastos del centro de arbitraje se encuentran cobijados por el amparo de pobreza?}

El inciso 2 del tan mencionado artículo 13 de la Ley 1563 de 2012 indica que el amparado por pobre quedará exonerado del pago de los honorarios de los árbitros y del secretario -en el evento en el que corresponda-, así como de los gastos del tribunal arbitral. De la sola lectura de la disposición normativa en mención salta a la vista que no se encuentran incluidos los gastos del centro de arbitraje dentro de los rubros que el amparado no debe asumir. Por lo anterior, resulta imperativo cuestionarnos acerca de si los gastos del centro de arbitraje se encuentran incluidos dentro del concepto de gastos del tribunal arbitral, y, por lo tanto, si están cobijados por el amparo de pobreza.

En primera medida, resulta pertinente anotar que las expensas o gastos del proceso en general son aquellos gastos que tuvieron que efectuarse para adelantar el proceso, tales como las sumas destinadas a

14 Es preciso señalar que no se encontró una regulación similar en el reglamento de otros centros de arbitraje colombianos. No obstante, la exigencia de cancelar gastos iniciales para presentar la solicitud de convocatoria de un tribunal arbitral es común. 
obtener la producción de determinada prueba, o las copias requeridas para surtir algún trámite (López Blanco, 2016, p. 1070). Como puede vislumbrarse, los gastos que deben pagarse a la institución administradora del arbitraje per se no corresponden con dicha definición.

En concordancia con lo anterior, es preciso también tener en cuenta que es común en los distintos reglamentos de los centros de arbitraje regular o prever los gastos del centro como un rubro adicional y diferente a los gastos del arbitraje y a los honorarios de los árbitros y del secretario. $^{15}$

En consecuencia, puede colegirse con palmaria claridad que los gastos del centro de arbitraje no corresponden a los gastos del tribunal o del proceso arbitral, y, por lo tanto, no se encuentran cobijados por el amparo de pobreza. Lo anterior tiene todo el sentido comoquiera que los centros, si bien administran el trámite del arbitraje, de ninguna manera administran justicia (Corte Constitucional, Sentencia C-765 de 2013, M. P.: Alberto Rojas; Corte Constitucional, Sentencia C-1038 de 2002, M. P.: Eduardo Montealegre). Así las cosas, quien solicite los servicios de un centro de arbitraje estará acudiendo a la celebración de un contrato de carácter privado, en el cual no tiene cabida la figura procesal del amparo de pobreza (Rodríguez, 2012, p. 13).

Sin perjuicio de ello, es menester cuestionarse acerca de si esta circunstancia resulta violatoria del derecho a la igualdad real entre las partes del proceso, cuya protección es uno de los objetivos de la institución del amparo de pobreza. Nuevamente, resulta de particular relevancia la tan mencionada incompatibilidad teórica entre el arbitraje y el amparo de pobreza, comoquiera que -como se anunció en antecedencia- si bien asumir los gastos del centro puede constituir una barrera para quien solicita el amparo de pobreza y debe acudir a un proceso arbitral para dirimir sus conflictos, lo cierto es que dada la naturaleza eminentemente onerosa del proceso arbitral, y al ser un

15 Ver los más relevantes: i) artículo 2.38 del Reglamento de Arbitraje Nacional del Centro de Arbitraje y Conciliación de la Cámara de Comercio de Bogotá, así como el parágrafo 8.3 del marco tarifario; ii) artículo 33 del Reglamento de Arbitraje del Centro de Conciliación, Arbitraje y Amigable Composición de la Cámara de Comercio de Medellín; y iii) artículo 27 del Reglamento de Arbitraje del Centro de Conciliación y Arbitraje de la Cámara de Comercio de Barranquilla. 
proceso adelantado y administrado por privados, hay gastos que necesariamente deben asumirse.

\section{Evento en el que ambas partes solicitan el amparo}

Dentro del análisis que venimos haciendo en este artículo de investigación sobre la operatividad del amparo de pobreza en el proceso arbitral dados distintos escenarios hipotéticos, resulta relevante preguntarse ¿qué pasa cuando ambas partes solicitan el amparo de pobreza en un trámite arbitral?

La Ley 1563 de 2012 no consagra ninguna disposición expresa que regule esta hipótesis. Por su parte, en el artículo 151 del CGP -expuesto en apartados anteriores - se establece que "el amparo podrá solicitarse por el presunto demandante antes de la presentación de la demanda, o por cualquiera de las partes durante el curso del proceso" (inciso 1), por lo que es claro que el legislador procesal colombiano no prohíbe que sea una o ambas partes dentro de un proceso judicial las que soliciten el amparo de pobreza cuando deban escoger entre garantizar su propia subsistencia o atender el proceso judicial, por lo que, de acuerdo con uno de los principios generales de interpretación de la ley, si el legislador no distingue no le es dable tampoco hacerlo al intérprete $\mathrm{u}$ operador jurídico que la aplica (Corte Constitucional, Sentencia C-317 de 2012, M. P.: María Victoria Calle Correa).

De esta manera, puede ocurrir, desde el punto de vista legal y práctico, que ambas partes soliciten ser amparadas por pobres en el marco de un proceso arbitral, por lo que, en este evento, el tribunal arbitral tendría que trabajar ad honorem (de manera gratuita) para resolver el caso concreto sometido por las partes a su conocimiento. Sin embargo, esta hipótesis iría en absoluta contravía a la naturaleza eminentemente onerosa del arbitraje y es poco probable que los árbitros decidan ejecutar su labor sin recibir honorarios a cambio.

En este punto, se hace necesario resaltar que, si en un escenario judicial ambas partes solicitaran amparo de pobreza, el proceso se podría desarrollar sin ningún inconveniente hasta la sentencia que resuelva de fondo el litigio, en la medida en que el servicio público de justicia del Estado es gratuito y los jueces son funcionarios estatales que reciben 
mensualmente un salario. No obstante, en el escenario arbitral, ciertos particulares administran justicia a cambio de unos honorarios. Así mismo, y habiéndose hecho una consulta previa y exhaustiva de fuentes, no hay legislación extranjera que trate del amparo de pobreza en el arbitraje.

\section{Evento en el que una de las partes se encuentra amparada por pobre en el proceso arbitral y la otra parte no consigna su porcentaje de honorarios y gastos}

Por otro lado, surge la siguiente pregunta: ¿qué sucede si, dentro del proceso arbitral, una de las partes se encuentra amparada por pobre y, una vez fijada la partida de honorarios y gastos por pagar a favor del centro de arbitraje y de los árbitros, la otra parte no consigna el porcentaje que le corresponde?

El artículo 27 de la aludida Ley 1563 de 2012 establece expresamente que, una vez fijados los honorarios y gastos a favor de los árbitros y del centro de arbitraje, cada una de las partes debe consignar lo que les corresponda a órdenes del presidente del tribunal arbitral dentro de los diez días siguientes a la firmeza del auto que fijó dichos honorarios. Si una de las partes no paga, la otra podrá pagar por aquella los honorarios, o si ninguna de las partes paga, se declarará terminado el proceso y se declararán extintos los efectos del pacto arbitral para el caso concreto.

De acuerdo con la disposición anteriormente mencionada, si una de las partes dentro del proceso arbitral no paga la parte de los honorarios y gastos del arbitraje que le corresponde sufragar, y la otra parte cumplió con dicha carga, esta podrá pagar el valor correspondiente por aquella dentro de los cinco días siguientes - sin perjuicio de que repita contra su contraparte ante la justicia ordinaria por dicho pago, o esta circunstancia sea tenida en cuenta por el tribunal arbitral al momento de fijar las costas procesales (Ley 1563 de 2012, art. 27, incs. 1 y 2)-, so pena de que se declare terminado el proceso, concluidas las funciones del tribunal arbitral y extinguidos los efectos del pacto arbitral para ese caso concreto.

Si se está en presencia de una parte amparada por pobre, es claro que, atendiendo a una interpretación sistemática del referido artículo 27 de la Ley 1563 de 2012, con el artículo 13 de esta ley y con los artículos 151 y siguientes del CGP, dicha parte debería considerarse, 
para efectos del pago de los honorarios y gastos del arbitraje, como una parte cumplida, en la medida en que se encuentra legalmente exonerada de pagar dichos conceptos. Sin embargo, el artículo 13 de la Ley 1563 de 2012 advierte, en su último inciso, que la contraparte no está obligada a pagar lo que al amparado por pobre le correspondía pagar, por lo que solamente tiene la obligación de pagar el porcentaje que le corresponda sobre la partida de honorarios y gastos.

Si dicha contraparte no consigna oportunamente el respectivo valor a órdenes del presidente del tribunal arbitral, de conformidad con el artículo 27 de la Ley 1563 de 2012, pueden producirse dos hipótesis: i) que el amparado por pobre pague el valor que le correspondía pagar a su contraparte; y ii) que el tribunal no reciba la consignación de los honorarios por ninguna de las partes.

Es improbable que la primera hipótesis se dé en la práctica, pues, partiendo de la procedencia del amparo de pobreza prevista en el artículo 152 del CGP, si una de las partes no puede atender el proceso arbitral y las erogaciones propias de este sin perjudicar su propia subsistencia y las de las personas a las que por ley debe alimentos, mucho menos va a poder sufragar la partida de honorarios y gastos que debía pagar su contraparte.

Frente a la segunda hipótesis, atendiendo a una interpretación literal del artículo 27 de la Ley 1563 de 2012, si el tribunal no recibe oportunamente las consignaciones de los honorarios y gastos del arbitraje de ninguna de las partes no se encuentra obligado a resolver el caso ad honorem, y podrá dar por terminado el proceso arbitral, cesar en sus funciones y declarar extinguidos los efectos del pacto arbitral para el caso concreto.

Esta hipótesis pone en evidencia que, si una de las partes dentro de un proceso arbitral se encuentra amparada por pobre, la contraparte en la práctica podrá enervar los efectos del pacto arbitral suscrito y podrá producir la terminación del proceso arbitral, obligándole al amparado por pobre a acudir a la justicia del Estado aun cuando su voluntad expresada en el compromiso o en la cláusula compromisoria era la de sustraer el conflicto de dicha jurisdicción. Estas particulares circunstancias demuestran aún más la incompatibilidad práctica del amparo de pobreza y del proceso arbitral. 


\section{¿Hay lugar a condenar en costas al amparado por pobre en un proceso arbitral?}

Si se realiza una comparación literal de lo dispuesto en el artículo 154 del CGP y de lo prescrito en el artículo 13 de la Ley 1563 de 2012, debe responderse de forma afirmativa a este interrogante. Por un lado, el aludido artículo 154 del CGP dispone expresamente que el amparado por pobre no será condenado en costas. Por el contrario, el inciso 2 del artículo 13 de la Ley 1563 de 2012 excluye expresamente el pago de costas procesales de los rubros que el amparado por pobre en un proceso arbitral estaría exonerado de pagar.

La disposición anteriormente mencionada indica claramente que el tribunal arbitral podrá condenar en el laudo al amparado por pobre a pagar costas procesales en favor de su contraparte en caso de perder el proceso. Consideramos que la intención del legislador civil en el CGP fue, de forma opuesta, la de exonerar al pago de gastos procesales (expensas) y del reconocimiento a la labor del apoderado de la contraparte (agencias en derecho) a todas aquellas personas que, por sus precarias o difíciles condiciones económicas, no pueden atender al mismo tiempo ningún pago derivado del proceso judicial y su propia subsistencia.

Sin embargo, para el proceso arbitral el legislador colombiano no siguió la misma lógica, por lo que este es otro escenario donde se puede evidenciar con gran facilidad la incompatibilidad entre este proceso y el amparo de pobreza como una figura inicialmente instituida para acceder de forma gratuita y en condiciones de igualdad a la administración de justicia.

\section{Eficacia jurídica de incluir el amparo de pobreza en el pacto arbitral}

Para abordar este acápite será necesario hacer una breve mención de lo que significa el pacto arbitral, con el fin de determinar qué pueden pactar las partes en él y si es posible que acuerden introducir la figura del amparo de pobreza a favor de alguna de las partes o de ambas.

De acuerdo con el artículo $3^{\circ}$ de la Ley 1563 de 2012, el pacto arbitral se define como "un negocio jurídico por virtud del cual las 
partes someten o se obligan a someter a arbitraje controversias que hayan surgido o puedan surgir entre ellas [...]". ${ }^{16}$

De esta manera, el pacto arbitral liga el arbitraje con el derecho privado, en especial con el derecho de las obligaciones y con la teoría del negocio jurídico, en la medida en que encuentra su génesis en la existencia de un acuerdo recíproco de voluntades para someter conflictos actuales o futuros a la decisión de un tercero que se denomina árbitro (Ramírez Gómez, 2016, p. 28). ${ }^{17}$ Según el profesor Cristian Larroumet, el pacto arbitral es un contrato muy especial que tiene por objeto un acto jurisdiccional (2005, p. 14).

En este sentido, si el pacto arbitral se define como un acuerdo de voluntades que tiene como objeto un acto jurisdiccional, en la medida en que pretende sustraer un determinado conflicto del procedimiento previsto ante los jueces ordinarios para que sea conocido por un tercero denominado árbitro, es claro que es posible que las partes pacten la forma de seleccionar los árbitros, la sede del arbitraje, la clase de laudo que desean que se profiera y los aspectos procesales aplicables a dicho trámite arbitral (de conformidad con el artículo 58 de la Ley 1563 de 2012, en tratándose de arbitraje entre particulares, es posible que pacten el procedimiento por seguir, atendiendo a los principios constitucionales del debido proceso, del derecho a la defensa y de igualdad procesal). Dentro de estos aspectos procesales será entonces posible que las partes acuerden incluir la figura del amparo de pobreza a favor de alguna o de ambas de ellas, $y$, de ser necesario, pacten aspectos que puedan hacer un poco más fluido el arbitraje ante esta circunstancia. ${ }^{18}$

Así mismo, y sin desconocer que la aplicación del amparo de pobreza al arbitraje tiene su sustento en la ley y no en el acuerdo de voluntades que hagan las partes, coincidimos con el criterio de la profesora Marcela

16 Ver también: Bejarano Guzmán (2019, p. 415).

17 Cfr. en similar sentido: “La naturaleza contractual del arbitraje y, por ende, el regreso a la 'tradición jurídica' en materia de arbitraje deben, en ese orden de ideas, ser reivindicados en Colombia. El arbitraje proviene de un contrato celebrado entre las partes de un litigio por medio del cual estas deciden que toda controversia que pueda surgir de un contrato o con relación al mismo debe ser sometida al conocimiento de un tercero llamado tribunal arbitral. Dicho contrato es denominado 'acuerdo de arbitraje' o, término más utilizado en nuestro derecho, "pacto arbitral" (Silva Romero, 2003, p. 294).

18 Cfr. en similar sentido: Rodríguez Mejía (2012, p. 392). 
Rodríguez Mejía (2012, p. 392) cuando afirma que, si el artículo 152 del CGP (aplicable por remisión expresa del artículo 13 de la Ley 1563 de 2012) permite solicitar el amparo de pobreza incluso antes de la presentación de la demanda, es posible acordar este beneficio a favor de cualquiera o de ambas partes en el pacto arbitral, teniendo en cuenta que la parte que haga uso de dicho beneficio y solicite el amparo junto con la demanda que convoca al respectivo árbitro o tribunal arbitral deberá manifestar bajo juramento (y recomendable acreditarlo) que se encuentra en condiciones de pobreza o de difícil situación económica, haciendo énfasis en que, si falta a la verdad, pueden existir consecuencias por realizar un juramento falso.

Sin embargo, consideramos que, aunque es amplio el poder de disposición en materia de normas procesales que tienen las partes a la hora de convenir un pacto arbitral, también es cierto que, como todo contrato, debe respetar el orden público, por lo que no podría pactarse la prohibición para alguna o ambas partes de solicitar el amparo de pobreza en el trámite arbitral comoquiera que esta disposición sería contraria al derecho al acceso efectivo a la administración de justicia.

Bajo estos presupuestos, es claro que, desde el punto de vista teórico y legal, es posible que se incluya un acuerdo sobre el amparo de pobreza en el pacto arbitral, no obstante, por los argumentos expuestos a lo largo de este trabajo, ponemos en duda la eficacia práctica de este acuerdo, en la medida en que resulta ser incompatible con el carácter oneroso del proceso arbitral.

\section{E1 arbitraje social}

El arbitraje social es una figura instituida en la Ley 1563 de 2012 con el fin de garantizar el acceso efectivo a la administración de justicia a los sectores más vulnerables, excluidos y de bajos recursos económicos de la población colombiana (Zamudio Arias, 2019). El artículo 117 de la mencionada ley establece que los centros de arbitraje autorizados por el Ministerio de Justicia y del Derecho deberán promocionar jornadas para la prestación gratuita del servicio de arbitraje social cuando la cuantía de la controversia no supere los 40 SMLMV, a través de procedimientos 
especiales, breves y sumarios, sin perjuicio de que los respectivos centros decidan prestar ese servicio para cuantías superiores.

Este artículo determina que el caso sometido a arbitraje social será decidido por un árbitro único, el cual deberá desempeñar su labor ad honorem; y no es necesaria la asistencia de un abogado, lo que suprime la necesidad de sufragar los honorarios del árbitro y de un apoderado judicial. Bajo esta línea, es posible afirmar que el arbitraje social busca, al igual que el amparo de pobreza, garantizar la existencia de una justicia real, efectiva e incluyente (Alonso, 2016), permitiendo a las personas de bajos recursos económicos o en condiciones de pobreza solucionar sus conflictos reduciendo costos.

Sin embargo, el arbitraje social no ha tenido mucha difusión en la práctica, a nuestro juicio, por tres razones fundamentales. En primer lugar, los centros de arbitraje tienen la necesidad de obtener los recursos para costear la infraestructura física y administrativa asociada a la prestación de este servicio arbitral. En segundo lugar, no es obligatorio garantizar el servicio de arbitraje social de forma continua, pues el servicio se presta a través de una o varias jornadas al año coordinadas entre los centros de arbitraje y el Ministerio de Justicia y del Derecho (Decreto 1069 del 26 de mayo de 2015, modificado por el Decreto 2462 del 17 de diciembre de 2015). Y, finalmente, no es claro dentro del citado artículo 117 si las personas de escasos recursos quedan exoneradas de pagar rubros por concepto de práctica de pruebas, expensas o gastos procesales. Todas estas circunstancias impiden ampliar la cobertura poblacional y territorial de este mecanismo alternativo de resolución de controversias.

Por esta razón, la Cámara de Comercio de Bogotá propuso la creación de convenios entre las alcaldías, los entes territoriales y el sector privado para ampliar la cobertura del arbitraje social, y la concreción de convenios con el Ministerio de Tecnologías de la Información y las Comunicaciones (TIC) para ofrecer los servicios de arbitraje virtual a los particulares a través de kioscos digitales (Cámara de Comercio de Bogotá, 2017, pp. 196-197).

Ante este panorama, es posible afirmar que el arbitraje social, al igual que el amparo de pobreza, es una herramienta judicial insuficiente en la actualidad para conciliar la onerosidad del arbitraje con el acceso 
completamente gratuito a la administración de justicia para las personas en condiciones de vulnerabilidad o que se encuentran en una situación económica difícil.

\section{Crítica a la regulación actual y posibles soluciones}

De conformidad con lo expuesto anteriormente, a nuestro criterio, el amparo de pobreza, a pesar de obedecer a un fin razonable y atendible como lo es la garantía del derecho al debido proceso y el acceso a la administración de justicia, no resulta aplicable ni operante en la práctica arbitral. Esto comoquiera que el arbitraje es generalmente oneroso, debido a que los árbitros - a diferencia de los jueces de la república- no reciben un salario por parte del Estado, sino honorarios por su gestión como particulares que transitoriamente están investidos de función jurisdiccional. Así las cosas, en el ámbito del proceso arbitral la institución procesal del amparo de pobreza no resulta una garantía real y efectiva del derecho a la igualdad y del acceso a la administración de justicia.

Esta conclusión se deriva de un estudio legal, jurisprudencial, doctrinal y de algunos casos prácticos que podrían producirse a la hora de emplearse el amparo de pobreza en el proceso arbitral, pues no existen cifras oficiales ni por el gobierno colombiano ni por los centros de arbitraje que permitan medir el impacto de la figura del amparo de pobreza en los procesos arbitrales. Por ejemplo, el Centro de Arbitraje y Conciliación de la Cámara de Comercio de Bogotá, en respuesta al derecho de petición de información radicado por las suscritas autoras, manifestó, mediante correo electrónico del 28 de junio de 2021, que el referido centro no tenía ninguna herramienta para medir internamente en cuántos de los procesos arbitrales que se llevaban ante ella se había concedido el amparo de pobreza ni en cuántos de esos procesos se había proferido laudo arbitral.

Sin perjuicio de lo anterior, la necesidad que justifica el amparo de pobreza subsiste. El hecho de que el arbitraje se caracterice por ser oneroso no es óbice para que en la práctica se presenten eventos en los cuales una o ambas partes vinculadas por un pacto arbitral se encuentren en imposibilidad de iniciar el proceso arbitral, dado que 
atender los gastos que se generen representaría un menoscabo de lo necesario para su propia subsistencia y la de las personas a quienes por ley debe alimentos.

En ese orden de ideas, se considera absolutamente necesario ampliar el espectro de aplicación de la figura del arbitraje social, analizada en el epígrafe anterior, con el propósito de garantizar en mejor medida el acceso a la administración de justicia de quienes se hallan en una precaria situación económica cuando se trate de un proceso arbitral. Así las cosas, resulta preciso que el arbitraje social se aplique no solo a las controversias cuya cuantía ascienda hasta 40 salarios mínimos legales mensuales vigentes, sino también a aquellas en las cuales una o ambas partes se encuentren en imposibilidad de atender los gastos del arbitraje dada su difícil situación económica, sin importar el monto de las pretensiones.

Si bien es cierto que el artículo 36 del actual Proyecto de Ley 9 del 20 de julio de 2021, que pretende modificar el Estatuto Arbitral, el cual se encuentra radicado en el Congreso, dispone que el arbitraje social procederá para cuantías de 100 salarios mínimos mensuales vigentes, sin perjuicio de que cada centro de arbitraje decida prestar este servicio para cuantías superiores, consideramos que es una solución insuficiente comoquiera que lo que se sugiere es que este mecanismo procesal aplique en hipótesis en las cuales, habiendo pacto arbitral, las partes no tengan cómo costear el proceso arbitral sin menoscabo de su propia subsistencia, sin importar la cuantía del litigio.

Así mismo, resultaría útil generar incentivos por parte de los centros de arbitraje para los árbitros que ingresen a la lista de árbitros voluntarios con el propósito de adelantar arbitrajes sociales, de manera que estos trámites puedan llevarse a cabo con mayor frecuencia y pueda abarcarse una cantidad mayor de controversias.

En suma, si bien consideramos que el amparo de pobreza no es una figura útil ni operante en el marco de un proceso arbitral, la regulación sí prevé una institución que responde a los mismos fines del amparo de pobreza, consistente en el arbitraje social. A pesar de lo anterior, el arbitraje social debe ser fortalecido, de modo tal que garantice en debida forma el acceso a la administración de justicia de quienes se encuentran en condición de vulnerabilidad o en una mala situación económica. 


\section{Conclusiones}

Las reflexiones presentadas a lo largo de este artículo nos permiten hacer las siguientes conclusiones:

1. El amparo de pobreza, entendido como aquella medida procesal que busca garantizar la igualdad real y material de las partes que se encuentran involucradas en un proceso judicial, y el acceso efectivo a la administración de justicia de aquellas personas que se hallan en difíciles condiciones económicas o en condiciones de marginalidad, no solo opera para personas naturales, sino que también puede ser empleado por aquellas personas jurídicas que no puedan acceder a la administración de justicia sin poner en peligro su existencia en el mundo jurídico ni entrar en liquidación.

Esto resulta relevante en el marco del proceso arbitral comoquiera que este mecanismo alternativo de solución de conflictos es mayoritariamente utilizado por personas jurídicas.

2. El proceso arbitral, como mecanismo alternativo de resolución de controversias, es eminentemente oneroso. Deferir la solución de ciertos conflictos a un tribunal arbitral implica para las partes asumir el pago de los honorarios de los árbitros y los gastos del arbitraje, lo que puede resultar un inconveniente para quienes no cuentan con la suficiente solvencia. El costo del arbitraje se fundamenta en que son particulares quienes conformarán el tribunal, los cuales naturalmente deben ser remunerados, así como también las partes deberán reconocer los gastos que genere el proceso, dentro de los cuales se incluirán los relativos al centro de arbitraje por la administración del trámite, en el evento en el que se trate de un arbitraje institucional.

3. En consecuencia, y sin pretender desconocer que el propósito del amparo de pobreza es la garantía de la igualdad real de las partes, sí existe una contradicción entre la naturaleza misma de esta institución, la cual implica que una de las partes no asuma los gastos del proceso por su condición económica particular, y el arbitraje, el cual se caracteriza precisamente por implicar ciertos costos para las partes, como consecuencia de su decisión voluntaria de no acudir a los jueces estatales para dirimir sus conflictos. Existen varias razones de orden teórico y práctico que nos permiten hacer esta afirmación: 
3.1. A pesar de que una persona sea amparada por pobre en el marco de un trámite arbitral, se le exige sufragar ciertos gastos iniciales del arbitraje a favor del centro de arbitraje (cuando el arbitraje sea institucional), los gastos administrativos del centro, y puede ser condenado en costas procesales.

3.2. Es probable, desde el punto de vista legal y práctico, que ambas partes soliciten ser amparadas por pobres en el marco de un proceso arbitral, por lo que, en este evento, el tribunal arbitral tendría que ejercer su labor ad honorem (de manera gratuita) para resolver el caso concreto sometido por las partes a su conocimiento. Sin embargo, esta hipótesis iría en absoluta contravía a la naturaleza onerosa del arbitraje y es poco probable que los árbitros decidan ejecutar su labor sin recibir honorarios a cambio.

3.3. Si una de las partes dentro de un proceso arbitral se encuentra amparada por pobre, la contraparte podría no consignar el porcentaje de honorarios que le corresponde, enervando en la práctica los efectos del pacto arbitral suscrito y provocando la terminación del proceso arbitral, obligándole al amparado a acudir a la justicia del Estado aun cuando su voluntad expresada en el compromiso o en la cláusula compromisoria era la de sustraer el conflicto de dicha jurisdicción.

4. Es posible que las partes acuerden incluir en el pacto arbitral la figura del amparo de pobreza a favor de alguna o de ambas de ellas, y, de ser necesario, pacten aspectos que puedan hacer más fluido el arbitraje ante esta circunstancia. No obstante, consideramos que, aunque es amplio el poder de disposición en materia de normas procesales que tienen las partes a la hora de convenir un pacto arbitral, también es cierto que, como todo contrato, debe respetar el orden público, por lo que no podría pactarse la prohibición o limitación para alguna o ambas partes de solicitar el amparo de pobreza en el trámite arbitral como quiera que esta disposición sería contraria al derecho al acceso efectivo a la administración de justicia.

5. El arbitraje social es una figura instituida en la Ley 1563 de 2012 con el fin de garantizar el acceso efectivo a la administración de justicia a los sectores más vulnerables, excluidos y de bajos recursos económicos de la población colombiana. Sin embargo, al igual que el amparo de pobreza, es una herramienta judicial insuficiente en la actualidad 
para conciliar la onerosidad del arbitraje con el acceso completamente gratuito a la administración de justicia para las personas en condiciones de vulnerabilidad o de difícil situación económica.

6. Sin perjuicio de lo anterior, la necesidad que justifica el amparo de pobreza subsiste. El hecho de que el arbitraje se caracterice por ser oneroso no es óbice para que en la práctica se presenten eventos en los cuales una o ambas partes vinculadas por un pacto arbitral se encuentren en imposibilidad de iniciar el proceso arbitral, dado que atender los gastos que se generen representaría un menoscabo de lo necesario para su propia subsistencia y la de las personas a quienes por ley deben alimentos.

7. En ese orden de ideas, se considera absolutamente necesario ampliar el espectro de aplicación de la figura del arbitraje social y fortalecer este procedimiento, de modo tal que se garantice en debida forma el acceso a la administración de justicia de quienes se encuentran en condición de vulnerabilidad o en una mala situación económica.

\section{Referencias}

\section{Doctrina}

Alonso, N. (2016). El arbitraje social en Colombia. Recuperado de http://www. colvyap.com/2016/05/el-arbitraje-social-en-colombia.html

Bennetti, J. (2001). El arbitraje en el derecho colombiano. Bogotá: Temis.

Huertas Montero, L. E. (2018). El amparo de pobreza en el Código General del Proceso. En AA. VV., Código General del Proceso. Ley 1564 de 2012. Comentado con artículos explicativos de miembros del ICDP (Vol. II). Bogotá D.C.: Instituto Colombiano de Derecho Procesal.

Larroumet, C. (2005). A propósito de la naturaleza contractual del acuerdo de arbitraje en materia internacional y de su autonomía. En AA. VV., El contrato de arbitraje. Bogotá D.C.: Legis-Colegio Mayor de Nuestra Señora del Rosario.

López Blanco, H. F. (2016). Código General del Proceso. Parte general. Bogotá D.C.: Dupre Editores.

López, F., \& Silva, R. (2018). El proceso arbitral en el derecho contemporáneo. Bogotá: Doctrina y Ley. 
Mancipe, M., E Hernández, I. (enero-junio, 2019). El principio de la autonomía de la voluntad contractual vs. el control jurisdiccional constitucional en los laudos arbitrales. Revista E-Mercatoria, 18(1).

Monroy, M. (2011). Arbitraje comercial nacional e internacional. Bogotá: Ediciones del Profesional.

Otero, L. (2019). El arbitraje como trámite especial y sus implicaciones procesales. En Memorias del Congreso Internacional de Derecho Procesal (pp. 435-467). Medellín: Instituto Colombiano de Derecho Procesal.

Quintero, L. (enero-junio, 2016). Controversias jurídicas a la luz del amparo de pobreza en Colombia. ¿Acceso a la justicia real y efectivo? Revista de Derecho Público de la Universidad de los Andes, (36).

Ramírez Gómez, J. A. (2016). La vinculación de sujetos no signatarios a los efectos del pacto arbitral. Bogotá D.C.: Universidad Externado de Colombia.

Rodríguez Mejía, M. (julio-diciembre, 2012). Una aproximación al régimen del arbitraje nacional del nuevo Estatuto de Arbitraje en Colombia, Ley 1563 de 2012. Revista de Derecho Privado, 379-417.

Sanabria, H. (2017). Los honorarios y gastos del tribunal arbitral y del árbitro. En H. Herrera \& F. Mantilla (Coords.), El árbitro y la función arbitral (pp. 289-312). Bogotá: Ibáñez.

Sánchez Arteaga, S., E Rodríguez Castillo, F. (2020). Eficiencia del arbitraje en la garantía del derecho de acceso a la administración de justicia. Via Inveniendi Et Iudicandi, 15(2), 277-297.

Uribe, C. (2013). El arbitramento en Colombia. En E. Vargas \& F. Gorjón (Coords.), Arbitraje y mediación en las Américas (pp. 143-159). Chile: Centro de Estudios de Justicia de las Américas.

Zamudio Arias, A. F. (2019). El arbitraje social como una herramienta para la construcción de paz. Boletín Virtual del Departamento de Derecho Procesal. Recuperado de https://procesal.uexternado.edu.co/el-arbitraje-social-comoherramienta-para-la-construccion-de-paz/\#: :text=E1\%20Arbitraje\%20 Social\%20es\%20una,excluidos\%20y\%20de\%20bajos\%20recursos

\section{Jurisprudencia}

Colombia, Consejo de Estado, Sección Cuarta. Auto 12701 de 2002, C. P.: Juan Ángel Palacio Hincapié ( $1^{\circ}$ de febrero).

Colombia, Consejo de Estado, Sección Cuarta. Auto Radicación 25000-23-27000-2006-01305-01(16313), C. P.: Ligia López Díaz (3 de mayo de 2007). 
Colombia, Corte Suprema de Justicia, Sala de Casación Civil. Auto 45 de 2003, M. P.: Silvio Fernando Trejos ( $1^{\circ}$ de agosto).

Colombia, Corte Constitucional. Sentencia C-059 de 1993, M. P.: Alejandro Martínez Caballero.

Colombia, Corte Constitucional. Sentencia SU-091 de 2000, M. P.: Álvaro Tafur Galvis.

Colombia, Corte Constitucional. Sentencia T-114 de 2007, M. P.: Nilson Pinilla Pinilla.

Colombia, Corte Constitucional. Sentencia T-799 de 2011, M. P.: Humberto Antonio Sierra Porto.

Colombia, Corte Constitucional. Sentencia C-317 de 2012, M. P.: María Victoria Calle Correa (3 de mayo).

Colombia, Corte Constitucional. Sentencia T-339 de 2018, M. P.: Luis Guillermo Guerrero Pérez (22 de agosto).

Colombia, Corte Constitucional. Sentencia T-608 de 2019, M. P.: Gloria Stella Ortiz Delgado.

\section{Normatividad}

Colombia, Congreso de la República. Estatuto de Arbitraje Nacional e Internacional [Ley 1563 de 2012] (12 de julio de 2012). DO: 48489.

Colombia, Congreso de la República. Código General del Proceso. [Ley 1564 de 2012] (12 de julio de 2012). DO: 48489.

\section{Normatividad extranjera}

Nicaragua. Código de Procedimiento Civil [Ley 902] (4 de junio de 2015). Uruguay. Código General del Proceso [Ley 15982] (1988).

Venezuela. Código Procesal Civil (1980).

\section{Otros}

Colombia, Cámara de Comercio de Bogotá. (diciembre de 2017). Informe final del diagnóstico del arbitraje en el territorio nacional. Recuperado de https:// metodosderesoluciondeconflictos.files.wordpress.com/2018/07/informefinal-diagnostico-de-arbitraje-en-colombia.pdf 
Colombia, Centro de Arbitraje, Cámara de Comercio de Bogotá. (28 de junio de 2021). Respuesta a derecho de petición de información, formulado por Luisa María Brito y Laura Huertas Montero.

Colombia, Centro de Arbitraje y Conciliación, Cámara de Comercio de Bogotá. (2017). Directiva 5.

Colombia, Centro de Arbitraje y Conciliación, Cámara de Comercio de Bogotá. (2021). Reglamento de Arbitraje Nacional.

Colombia, Centro de Conciliación, Arbitraje y Amigable Composición, Cámara de Comercio de Medellín. (2014). Reglamento de Arbitraje.

Colombia, Centro de Conciliación y Arbitraje, Cámara de Comercio de Barranquilla. (2014). Reglamento de Arbitraje.

Colombia, Congreso de la República. Gaceta No 312 de 2012.

Colombia, Congreso de la República. Proyecto de Ley 9 del 20 de julio de 2021, "mediante el cual se modifica la Ley 1563 de 2012, Estatuto de Arbitraje Nacional e Internacional". 